\title{
The impact of university incorporation on college lecturers
}

\author{
L.R. BECKER, L.D. BEUKES, A. BOTHA, A.C. BOTHA, J.J. BOTHA, M. \\ BOTHA, D.J. CLOETE, J.L. CLOETE, C. COETZEE, L.J. DE BEER, D.J. \\ DE BRUIN, L. DE JAGER, J.J.R. DE VILLIERS, C.M. DU TOIT, A. \\ ENGELBRECHT, R. EVANS, M.M.C. HAUPT, D. HEYNS, L.M. \\ HOWATT, A.P. JOUBERT, J.C. JOUBERT, A.C. NIEMANN, N.C. \\ PHATUDI, E. RANDALL, W.J. RAUSCHER, W.C. RAUTENBACH, S. \\ SCHOLTZ, J.C. SCHULTZ, R. SWART, H.J. VAN ASWEGEN, J.C. VAN \\ HEERDEN, W.J. VAN VOLLENHOVEN, E.M. VAN WYK, J.G.U. VAN \\ WYK, C.A. VAN DER WALT, C.N. VAN DER WESTHUIZEN, D. \\ VERMEULEN \& A. VORSTER ${ }^{1}$
}

School of Teacher Training - Faculty of Education, University of Pretoria, Pretoria 0002, South Africa

\section{Introduction}

While there is a small but growing literature on "mergers" in higher education (Eastman and Lang 2001; Harman 2000; Goedegebuure 1992), very little research has been devoted to the impact of such events on the personal, emotional and career experiences of the staff who live through such processes. The existing literature tends to focus on the organisational goals and consequences of mergers (Kirk 2000) and, to a lesser extent, on the fusion of divergent campus cultures (Harman, in press). Little has been written, however, on what Buono and Bowditch (1989) refer to as "the human side of mergers and acquisitions".

In South Africa, recent government plans to change the institutional landscape of higher education through strategies that include mergers, have spawned a new field of studies on the origins, motives, processes and outcomes that result from combining various kinds of institutions (Kotecha and Harman 2001; Reddy 2001; Habib and Parekh 2000). Only one local study (using a questionnaire) examined the perceptions of staff about an impending three-college merger (Hay, Fourie and Hay 2001) and researchinprogress on six case studies of mergers (Bandi et al. 2002) promises to yield data on, among other things, the experiences of academic, administrative and technical staff during the course of various merger processes.

The research reported in this article focuses solely on the impact of a 'college-into-university' incorporation on the personal and career experiences of the staff of that College. It traces the perceptions and emotions of College staff during and directly after the incorporation process. It also identifies recurring themes and issues that surface in the personal lives of those affected by the incorporation of colleges into universities. As such, this 
research offers the first empirical study on 'the human side' of mergers ${ }^{2}$ in African higher education.

\section{Background}

Until recently, the more than 120 colleges of education in South Africa served 80,000 students and were legally regarded as 'a provincial competence' (Parker 2001). That is, colleges were the responsibility of the nine provincial governments in the province where those colleges were located. The provincial government therefore employed the college staff, owned the college buildings and governed the college curriculum. As of 1 January 2001, colleges were required by new legislation to either close or be incorporated into higher education institutions, like universities, the latter institutions (together with technikons) being 'a national competence' according to the Constitution, i.e., falling directly under the control of the national Minister of Education. On 27 July 1998, the Executive Council of the former Onderwyskollege Pretoria ${ }^{3}$ (College of Education Pretoria) passed a resolution supporting incorporation into the University of Pretoria (UP) ${ }^{4}$ with which it had had a historical association since 1978. On 24 June 1999 the Minister of Education announced his decision to incorporate the College as a sub-division of the University, granting all stakeholders ninety days to make representations in this regard. A preliminary report drafted by the stakeholders, (the College, UP, provincial education department and National Education department) was submitted to the Minister on 22 October 1999. In January 2001 the College was legally incorporated into the University and became part of the Faculty of Education. Enrolment of new students on the University system had already started taking place in 2000 , although academic staff officially only become part of the UP complement in January 2002. As part of the incorporation agreement, the Faculty relocated to the former College campus in October 2001, which then became known as the Groenkloof Campus of the University of Pretoria.

Of the ninety academic College staff posts, only forty-seven positions were earmarked ${ }^{5}$ for advertisement on the closed vacancy list, i.e., only College staff were eligible to apply in the first round. Finally forty-three College staff members were appointed on either a permanent (32) or contract basis $^{6}(11)$ on the closed vacancy list. The remaining posts were either discarded or advertised on an open vacancy list, thereby creating opportunities for scholars from other universities and colleges to seek appointment to the Faculty of Education (UP). College staff members who had not been appointed, could either apply for voluntary mutually agreed severance packages (MASPs) from the provincial government, in this case, the Gauteng Department of Education (GDE), or be re-assigned to a GDE district office elsewhere in the province. A small number of College staff members resigned. This number included both those who had been offered posts as well as those who had not. The College staff and new staff appointed from the open vacancy list were then located in a newly created School of Teacher Training (responsible mainly for undergraduate, pre-service education) while the pre-incorporation University staff, as well as a series of 
new appointments, were housed in a School of Educational Studies (responsible mainly for postgraduate, in-service education).

\section{Research strategy}

The College staff who had been incorporated into the Faculty of Education had always regarded themselves as undergraduate lecturers who prepared young student teachers for the profession. These College staff members were now required to collectively assume another identity: that of education researcher. Following the incorporation, daily research training and development workshops were organised to equip the former College staff with the skills necessary to become researchers, writers of academic articles and, as a result, publish and qualify for academic promotion in a university environment. ${ }^{7}$ During one of these training sessions, it was agreed that the College staff would research their own experiences of incorporation as an opportunity for becoming skilled at designing and conducting in-depth interviews - the topic for that weeklong training workshop. They identified seven critical themes as germane to an analysis of their experiences of incorporation and potential interview questions were generated through an intensive process of dialogue among themselves. This process was in itself risky and emotional for some, since it called for structured reflection on a painful process. Others welcomed the opportunity to speak openly about their experiences, for the first time, in a public (albeit research) forum. Eventually, seven standardised key questions were formulated with appropriate "prompts" that would guide each of the thirty interviewers. In addition, respondents would be asked to identify one critical incident that was prominent in their experience of the incorporation process. The interview protocol was then piloted through an in-class simulation exercise after which the researchers (that is, the former College staff) conducted semi-structured interviews with their colleagues. Each of the interviewees had by now been employed in the University either on a contract or permanent basis. The interviews were transcribed, and thirty data sets were brought back into the workshop for analysis. The researchers searched for convergent and divergent patterns of responses for the theme allocated to that team for analysis, e.g., the impact of incorporation on the family life of the respondent. Each research team (allocated to one of the seven theme areas) was also asked to extract substantial quotations or meaningful remarks they found particularly potent in describing a specific finding. The findings for each analytic theme were circulated for confirmation, elaboration or change to the thirty-eight staff members in training. A small team of writers collated all the smaller drafts into a coherent draft, before being submitted for publication. This article is the product, therefore, of those who had lived through, and then researched and written about the impact of incorporation into a university on their individual and collective lives.

\section{Main findings of the study}

The interview protocol was organised to collect data on the following broad theme areas, viz. impact on the professional domain that included finances, self-image and relationships; especially with management structures. The 
impact on the personal domain touched on aspects such as family life; emotions; and the effect on College lecturers' lives within the community. The reporting on the main findings follows the listing of the theme areas while comments on the critical incidents are interwoven into the narrative.

\section{Impact on professional work and relationships}

The work experiences of College staff during the incorporation process were uniformly described in the most intense emotional language. Despite these strong feelings about their work situation, the College lecturers nevertheless claimed that a strong "pligsbesef" (sense of duty) informed their general attitudes towards work and that they tried throughout, to deliver high quality teaching on a professional basis. They especially stressed the need to demonstrate positive attitudes within the classroom situation. A minority of the respondents referred to experiences of withdrawal and indifference.

In terms of their relationships with students during the incorporation process, the College lecturers affirmed the general tendency, i.e., to generate a positive attitude within the lecture rooms and to display spontaneity and enthusiasm in their teaching. However, they also acknowledged that negative attitudes or expressions often slipped through unconsciously during their teaching. About a third of the respondents argued that they made a conscious decision not to discuss the incorporation with their students, but that the issuance of general compliments and empathies by the students revealed that the staff members must have betrayed their awareness of the situation to students who themselves were uncertain about their futures. Only four of the thirty respondents openly discussed the incorporation with the students to motivate and encourage them regarding the positive aspects of the incorporation, e.g., that students could receive degrees rather than diplomas in future by earning extra credits.

In terms of their relationships with their colleagues, the experiences retold and expressed were very different from what prevailed in the company of students. Most of the College staff expected to be successful when applying in the first round, i.e., the closed vacancy list. The reaction among contract appointees at not being employed permanently ranged from 'total disbelief' (Interview 7) to "I cannot accept what happened ..." (Interview 21) to "the security rug was ripped from under me ..." (Interview 2) to "a feeling of panic and being left behind ..." (Interview 24). The relationship between contract appointees and permanent appointees was strained and communication stopped between these two groups while aggression was sometimes experienced. This period was often described as "abnormal". Even five months after the incorporation, feelings of tension were still felt by some of the College staff. Almost a quarter of the respondents also reported feelings of guilt in relation to their colleagues who had not received any appointment at all, to such an extent that some felt a reluctance to celebrate their new positions when others had been left out of the new Faculty.

Yet it remains striking that the incorporated College staff also experienced 
some degree of alienation in relation to the University staff who entered the new arrangement. More than half the College staff (56\%) felt that 'fullblooded' University staff "looked down" on them (Interview 12), were "antagonistic and maintained an air of academic superiority" (Interview 28). In the words of former College lecturers: "there is constant talk about "the college mentality ..." " (Interview 28) and "... in their eyes we are simply glorified primary school teachers" (Interview 12). Several staff claimed at the time of the interviews to still experience feelings of uncertainty and mistrust, and even perceptions of exclusion "on our own campus" (Interview 9). As this person elaborated elsewhere:

This was our campus and [we] felt that it had been taken from [us] especially when the changes were made to the buildings. When the floors were washed with ammonia, a student remarked that she felt as if UP wanted to wash away everything that had been NKP. (Interview 9)

In summary, the incorporated staff maintained largely positive attitudes towards their work and their students, but found increasing tension and strain between contract and permanent appointees, and between former College staff and the University staff from the main campus who occupied 'their' (that is, the College) campus.

\section{Impact on finances of college lecturers}

For some of the College staff, the financial implications of incorporation were devastating. The first trauma concerned the uncertainty of the financial status that accompanied the various options available, i.e., accepting: a severance package from the GDE, employment at the GDE or a University appointment, if granted. In addition it was uncertain whether any appointment from the University was to be granted in the first place. The long period of uncertainty was especially serious for the main employee in the family, as one recalled:

From the perspective of the breadwinner and taking into consideration my age, most of my thoughts and discussions with others revolved around feelings of fear ... I do not think people realise what tension, fear, stress and anxiety there actually was ... Before Iheard thatlhad received a contract appointment, there were a number of weeks in which I had no idea what the future would hold for me, including my financial future. I was rather concerned about my financial situation. (Interview 2)

This anxiety was especially intense depending on the individual family circumstances of the College staff.

The fact that I would have to resign and take a "package" would have been more beneficial in the sense that I could be relieved of responsibilities like the bond on my house; but there were also fears that since my children were still studying, I would then have had to seek another income at short notice. (Interview 22) 
This sentiment was supported several times as a critical factor in staff concerns about the outcome of the selection process:

If I did not receive an appointment at the University or a departmental post in Pretoria, we would have been seriously disadvantaged financially, especially since we have children studying and that implies a huge expense. Without my salary income, we would be in serious trouble. (Interview 25)

The general (though not uniform) experience was that the College staff were worse off in terms of "cash-in-hand" than they had been under the college system. Many of the staff members were appointed at university entry level (lecturer) irrespective of their senior appointments previously held in the College. This created feelings of a broken trust, since many College staff recalled being promised by the University management that none of them would be worse off as a result of the incorporation: "despite assurances by the University of Pretoria management, my financial position has weakened considerably" (Interview 11).

Anger was expressed towards the labour unions for not actively intervening in the financial negotiations of College staff and neglecting to enhance the security of their positions. As one recalls, "Most unions, and without my making any generalisations, did not play their part - and that after all the years in which I had contributed as a paid member of the union" (Interview 18). These concerns remain for many staff, especially those holding contract appointments. Such concerns include questions about whether the contract would be renewed in the future and whether age would count against a contract appointee on review of the position. It was further clear from the interviews that many older staff members could simply not afford to take early retirement or be relieved of their contract positions as they had not accumulated enough savings or retirement funds to leave fixed employment. Moreover, there was a keen awareness among many staff that generally employment possibilities were very limited, and that not enough would be accumulated by working "from home" (Interview 23). In the end, retaining college salary levels was crucial for many staff; as one exasperated respondent offered: "I will work for the same salary - even as the gardener" (Interview 12).

Strikingly, there were many staff members who found themselves better off financially than under the college system. One reported that: "... for the first time in my life I feel that I am being paid for the work that I do" previously this respondent received the lowest salary in her department and "[she] now [wishes] to buy a car, but simply cannot find the time to buy the damn thing" (Interview 10). One respondent claimed that "work is a vocation" and insisted: "[I] never really looked at what I was earning" (Interview 6). In addition, another of the benefits of working at the University is that the children of employees do not pay tuition, and this perk would therefore override other concerns. 
It is clear that the combination of free university studies and the favourable leave conditions provided a soft-landing for many of the College staff. It is also clear that the financial implications were more severely felt among senior College staff members who were actually re-employed at university entrance levels with lower salaries and diminished prestige. Very junior staff, however, found their financial situation improved as they were "bumped upwards" with respect to university salary scales.

\section{Impact on self-image and identity}

The inquiry as to the impact of the incorporation on the self-image and professional identities of the College staff yielded decidedly mixed results. There was clearly a group of staff members who felt that their self-worth and self-image had been dented by the incorporation, expressing themselves as follows: "My self-image was damaged, because I was no longer good enough. I felt that I was no longer good enough" (Interview 19) and "My self-image and personal value took a hard knock. It is never a nice feeling that you were not good enough .... th took me the better part of eight months to again feel a measure of self-worth and to function optimally in my work" (Interview 2).

These feelings of inadequacy were matched, however, by equally assertive comments on a steadfast self-image through the incorporation process: "In light of the fact that I believed that I would get a post, my self-image was not affected in the least. Up to the point before the interviews, I experienced no stress concerning the whole process" (Interview 7).

These positive feelings about self and identity clearly improved as news of the appointments reached the College staff members who had been selected: "For me the incorporation process is an extremely positive experience. The emotional impact on me is that I feel I am regarded as a human being and I am treated with integrity. ... The appointment at the University positively influenced my self-concept and self-image" (Interview 28).

Nevertheless, the incorporation led to some very deep soul searching and personal evaluations about College staff members' own abilities and even their self-image. Three different interview selections draw out this point:

The process itself did not affect my self-image or self-worth but it did cause me to reflect on myself. I did a lot of introspection and tested myself. (Interview 8)

There was constantly a searching self-investigation as to whether you measured up to the task. (Interview 6)

... I searched for answers within myself and my self-image was and still remains sunken in the ground. How I saw myself and what I thought they (after the interview) thought of me, finally pulled the rug from under my being. (Interview 21)

The question that kept coming through the reading and re-reading of the 
interview data was how exactly the College staff measured their self-esteem, i.e., the parameters they were using to judge their own image or self-worth. In judging themselves, they applied six critical factors:

First, College staff measured their self-worth in relation to the racial and institutional hierarchies of the organisations in which they worked. College staff who had worked at "black" colleges (in Laudium and Soshanguve) felt that they were regarded as inferior by staff at the former "white" College (NKP) to which they had been previously redeployed: "Those of us who came from the other colleges three years ago always felt that we were looked down on and thought that we would probably not be found good enough to be taken in at TUKS" (Interview 23).

As is evident in this selection, another institutional status and self-image problem now had to be confronted: that of the established College being incorporated into the University:

The incorporation process had a very negative influence on my selfimage and personal self worth. Fellow colleagues from the University informed me, for example, that College support services and their staff were held in low esteem and, from a professional point of view, were not regarded as having much value $p$ whereas before I was held in esteem in my position [at the College] and felt proud about my work, I am now constantly overlooked with respect to important decisions and daily meetings. (Interview 11)

Second, College staff measured their self-worth in relation to the reactions and valuation of their students:

The fact that I continued working with them [the students], and that I received much appreciation from them for what I do, assisted me to think less poorly about myself. It also helped me that they were glad when they found out that I would be teaching them again this year (Interview 13) and It is just too wonderful how students supported me with their sympathetic approaches and comments. (Interview 23)

Third, College staff assessed themselves in relation to the academic demands set by the University into which they had been incorporated. The research tasks, especially, influenced how they thought about their academic competence. Respondents experienced feelings of inadequacy and even incompetence: "I thought a University was for professors and intellectual giants" (Interview 23) and "When the Dean addressed us in the auditorium and introduced the research policy ... it made me feel insecure and I felt badly about myself" (Interview 20).

Yet other respondents saw opportunities in the new challenges: "In the previous dispensation I could not grow as a person ... now there is so much more to do. The promise this holds makes me feel good about myself" (Interview 24). 
Fourth, the type of appointment offered also had an impact on the selfesteem of the College lecturers. The following quotation from the interview data set is illustrative of the fact that contract appointees felt less sure of themselves than permanent staff:

I experienced a feeling or degree of inferiority. Was I found to be lacking? (Interview 17)

Not surprisingly, permanent appointees often felt more secure in their selfimage given the nature of their appointments: "It had a tremendous positive effect on a person's self-image because one knew that one had obtained work" (Interview 28).

Finally, the level of remuneration clearly influenced feelings of self-worth among many staff, as one explained: "As a result of the sharp decrease in salary and the decline in my working conditions, I question my own capabilities and as a result I no longer attach value to the things that I do" (Interview 11).

These perceptions of their self-worth were at times contradictory. On the one hand, respondents might claim that their self-esteem was not affected by the incorporation; yet further on in the interviews feelings of inadequacy nevertheless surfaced:

But I must say that it [the change process] did not really affect my selfimage because I do not allow myself to be disturbed by presumptuous ideas that are not grounded in substance. I know, after all, what I know. But as far as Tuks is concerned, I did not really think that I was good enough. (Interview 23)

In the course of time, however, many staff members tried to make the best of their situation, and to commit to the work at hand: "My classes simply continued as normal and I knew that I had a task to accomplish and, you know, if you keep your eye on the dream, and you maintain your vision, your work remains a wonderful therapy and joy" (Interview 26).

\section{Impact of the management on college staff}

Unlike the spread of emotions on the other themes, respondents were unanimous in their attitudes and feelings towards Management. Although the reference to management primarily implied the Executive Councils of the College or the University, it in some instances refereed to departmental officials and even union leadership; in short all those "powers-that-be" involved in the incorporation process. Deep and widespread feelings were expressed about dishonesty in the communication of management, the issuance of empty promises that were not fulfilled, the lack of participation by staff members in decisions affecting their future and a general lack of transparency in the process. The block of quotations, selected from different interviews, is best presented as such, before taking the analysis further: 
There was a hidden agenda ...(Interview 22)

... every person involved simply saw to their own interests ...

"... we never really knew whether the person who was acting on our behalf was entirely honest ..." (Interview 3 )

...we never received the correct information ...(Interview 9)

... dishonesty and deception on the part of the management ... (Interview 12; see also interviews 13 and 18)

...a non-transparent process was followed ...(Interview 10)

...little understanding was shown in extremely sensitive circumstances ...(Interview 2; see also interview 11)

... unilateral autocratic decisions were taken and enforced ... (Interview 11)

... we were not kept informed about the process at all ... the input of the [College] Rector was futile - the decisions had already been

taken and he could do nothing about it ...(Interview 14)

The data underline the uniformly negative perceptions of the transitional management. There were strong expressions about them as persons as many staff members felt they had been betrayed by them. With regard to process, strong feelings were expressed about the lack of information. Either way, the effects of the management of the process linger long after the incorporation: "There is still resentment and bitterness because things did not transpire as everyone hoped they would ... I have no respect for them and wish I could have the opportunity to say it to them face-to-face" (Interview 13).

There was, as noted earlier, a feeling of betrayal: "They [the previous management] made me feel self-assured and certain about my future. After the interviews had been conducted I felt that they had misled me and the institution as a whole" (Interview 7).

It is clearly not the purpose of this research to carefully evaluate the validity of each and every perception. Nevertheless, the research task was to delve into and describe perceptions, as one method of evaluating the impact of the incorporation of College staff into the University environment. It is these trenchant expressions and experiences of the management of incorporation that could possibly affect the ways in which incorporated staff view the current management of the new entity, i.e., the incorporated Faculty of Education. 


\section{The impact of incorporation on the community lives of the college staff}

The impact of the incorporation on the community life and standing of the College staff was the most dispersed in the data set. That is, most staff reported experiences that differed widely from those of their College counterparts. Almost half the respondents declared that the incorporation had no effect on their lives and status in the community. A number of respondents claimed, though, that they had to reduce their community commitments because of the added responsibilities in the University environment. Yet another group recall an initial reduction in their community activities, because of workload, but that they had since adjusted and assumed greater community involvement again. In terms of community reaction to their plight, the responses were also very diverse. Some regarded the community as apathetic, even negative towards their experiences; others recalled sympathetic and supportive reaction from, e.g., their church community. Several reported feeling pressure as a result of the public knowledge of their uncertain status with the incorporation. A common expression within this latter group was described by one of the respondents as follows: "... something like this is picked-up very quickly in the community in which you move, such as the church and sports events. It makes it even more difficult in that so many people constantly ask you how far the process has unfolded" (Interview 1).

Despite this response, there was no clear or dominant pattern of responses among the thirty interviewees; rather, the experiences among the incorporated College staff members on all aspects of community life and regard are mixed.

\section{Impact on family life}

Without exception, the incorporation process had a profoundly negative effect on the families and the domestic lives of the College lecturers concerned. Most respondents recall their families witnessing their feelings of (words drawn from the interview data) "insecurity, inadequacy, despondency, helplessness, stress, irritability, frustration and uncertainty" (across all interviews). One respondent described himself as acting like "a buffalo with a sore tooth" [sic] (Interview 13) in his family circle during this period; another remembered vividly that "I had very little patience and exploded and started crying at the slightest provocation" (Interview 9). Most respondents also recalled that spouses and family members tried their best to provide support and attempted to demonstrate empathy and express understanding for the difficult situation of the lecturer in question (Interview 13).

But such expression of support was not without tension, anger and recriminations experienced within the family circle. For example, one respondent (Interview 16) recalls feeling resentment at her husband for telling her that since there was no way the family could possibly function properly under the altered circumstances, she should simply resign herself to the status quo. Nor did the expressions of support alleviate the pain being felt; as another respondent recalls, the optimism and boundless faith of her family 
contradicted her feelings of anxiety and insecurity and, as a result, she felt that she had to cope with the realities of her situation alone. Even so, respondents claimed an acute awareness of the impact of the tension and uncertainty on their family members. As one recalls, "my children felt threatened by their mother's fatigue, loss of motivation and narrow view of things" and "they even said occasionally that I must not take out my frustrations on them" (Interview 12). Another colleague recalls painfully that she found herself turning a blind eye to her child's needs (Interview 10). Many respondents tried to manage their emotions within the family context: one, for example, insists that she tried to put on a brave face for the children's sake and did not refer to matters of work at all (Interview 8).

A second round of difficulties faced those who had found employment in the University. They now had to adjust to a very different schedule, different demands on their time and different responsibilities - such as becoming researchers. Respondents expressed concern about the extended hours spent on campus; others complained that domestic duties were not being completed, something that had been possible before incorporation. Many respondents were concerned that research time would, in future, leave them with less quality time to spend with their children. The following quotations are illustrative of the experiences of staff in this regard: "...the situation at work is all that I could talk about at home ... I remain mother and wife and human being; and then I have to ask myself: is this all worthwhile?" (Interview 9) and "The change in work had an enormous influence on my family. This is an entirely new ball game" (Interview 20).

The first critical observation about the data generated on the effects of incorporation on the family, was the intensity and unanimity of the individual experiences of the affected College lecturers. The second key observation is that the incorporation had very significant effects on personal and familial lives with respect to the variable of time; lives had to be re-organised to fit the pace and schedule of university life compared to college life. There was very little preparation of College staff to deal with both phases of the incorporation.

\section{Impact on emotional life}

In addition to their family and professional lives, the emotional lives of the incorporated College staff were thrown into constant turmoil. The interviews were replete with emotionally charged language that described the state of the persons who lived through various phases of the incorporation process. These two excerpts from respondent transcripts spoke for many:

I think the entire process comes down on you as a person. Probably because of the fact that your entire future is affected by it. If, for example, I told you that I lived through every conceivable emotion then I would not be exaggerating. There were times in which I was so reckless that I simply did not care about the whole event. If I now think back then that was a very dangerous time in my life. (Interview 1) [emphasis added] 
Another respondent could not think of a comparable experience:

This was definitely the most traumatic event in my life. It felt as if the security rug was plucked from under my feet. The emotional impact more than anything else was the worst aspect of the entire process ... For me the following emotions were always in the foreground: shock and disbelief, heartache, disillusionment, remorse, intense introspection, rage, depression, acceptance. (Interview 2)

Because of the intensity of College staff expressions, the research team that captured and analysed the emotional impact data clustered key terms to provide an overall portrait of the emotional terrain of incorporation. This analysis is reflected, for all thirty data sets, in Figure 1.

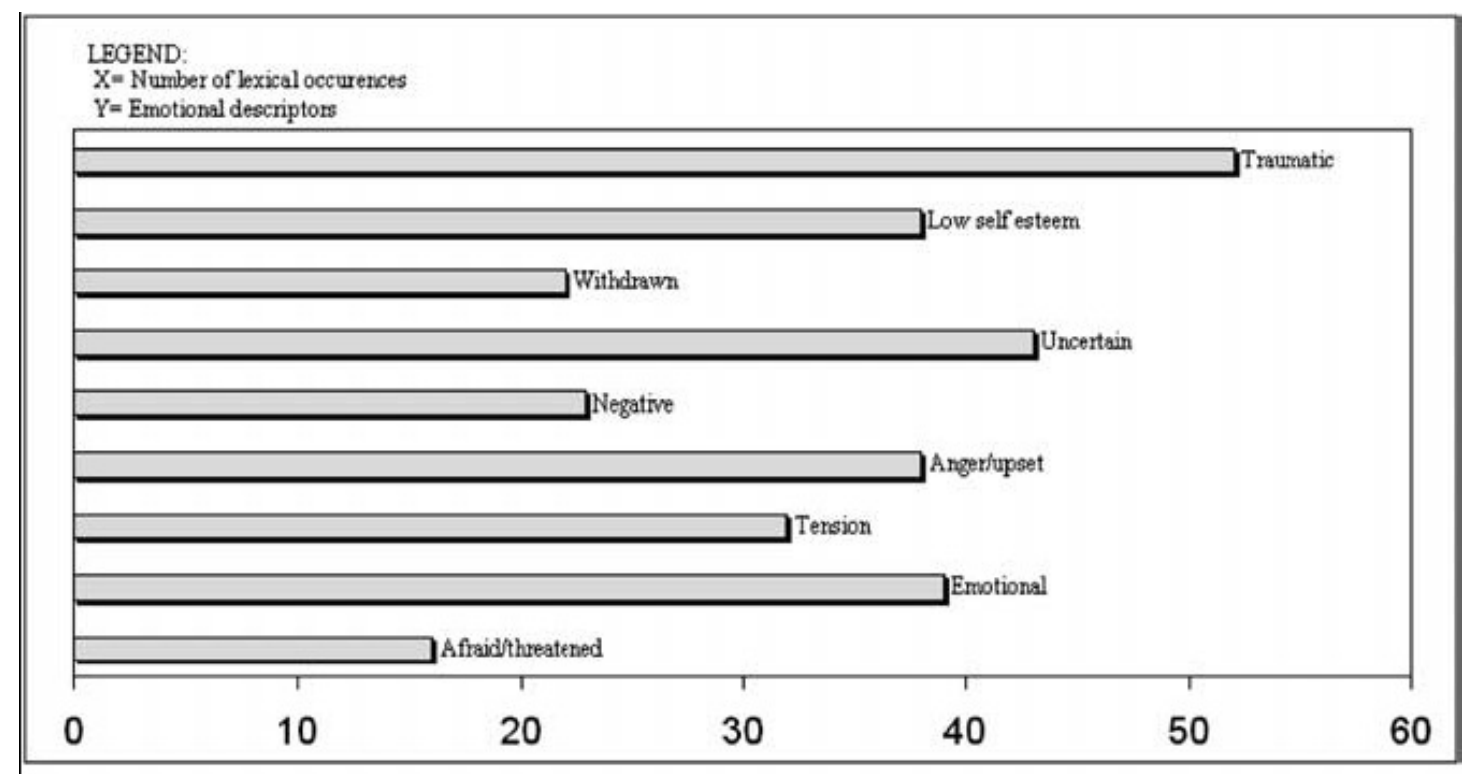

Figure 1. Negative emotions with the highest frequency.

What is noteworthy about the record of negative emotions is that at first 'uncertainty' emerged as the most frequently recorded emotion but as similar words were clustered in the analysis, 'traumatic' appeared more often as a result of the capturing of related terms such as grief, scars, trouble and others. Similar expressions of trauma could be found in powerful quotations such as:

I think the process was inhumane and I never again want to go through something like this in my life. (Interview 14)

Everything I had planned, was destroyed ... All my dreams for the future collapsed in ruins within moments. (Interview 21)

...dit het my oud gemaak. (It aged me - Interview 2 \& 13)

The data clearly suggest that the emotional impact of incorporation was personally intense. The uncertainty, especially, led to considerable trauma, 
and staff frequently felt frustrated and fatalistic. Yet it would be misleading to simply paint a picture that represented negative emotions, since some positive emotions were also expressed during the course of the incorporation. Such positive expressions can be represented as in Figure 2.

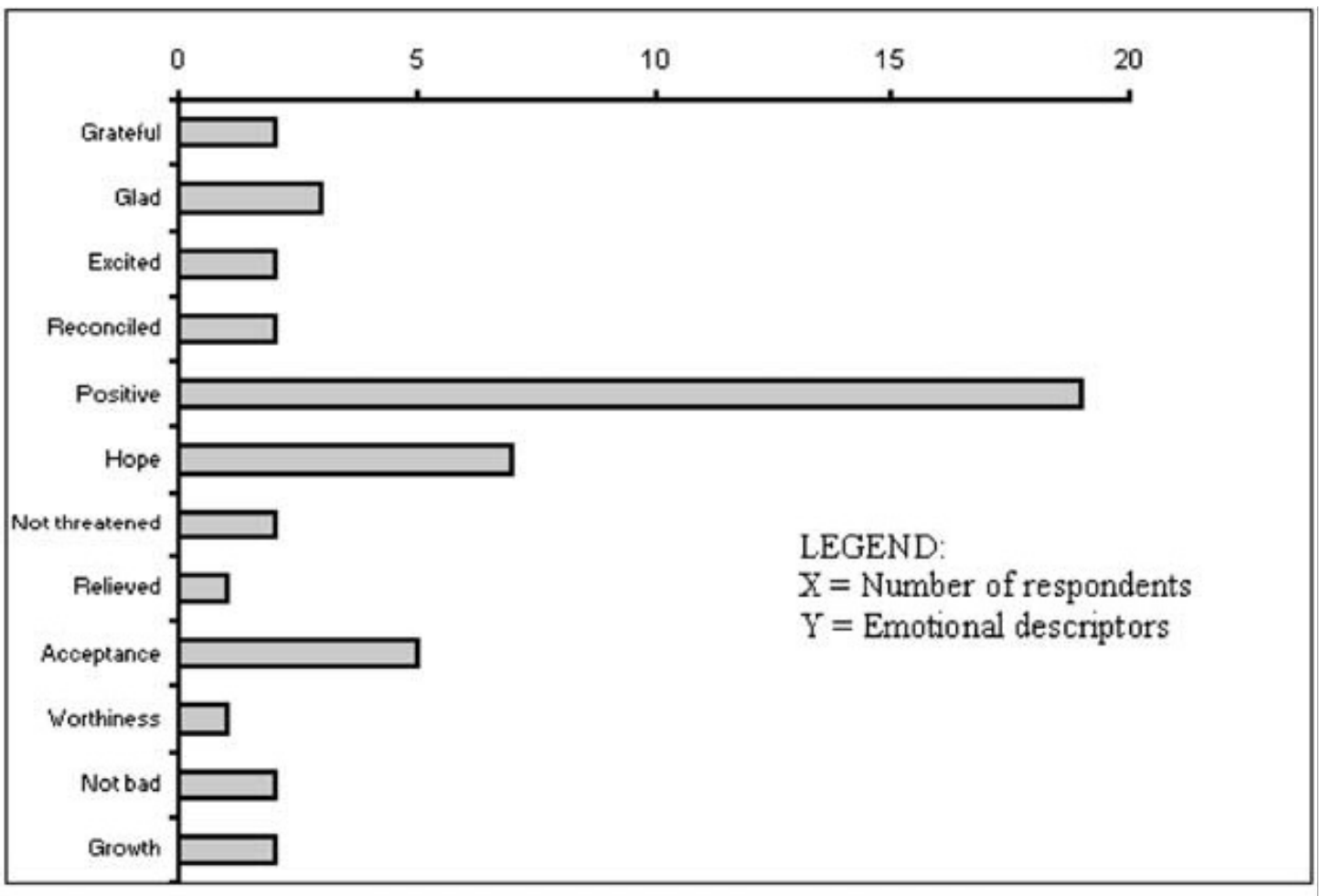

Figure 2. Distribution of positive emotions.

Certain staff members clearly remained positive about the incorporation despite the growing gloom. As time went on, some became very thankful that they had been selected and they expressed a sense of calm and even enthusiasm. Some remained hopeful throughout, unthreatened by what was happening around them, others experienced a sense of relief and a feeling of affirmation and acceptance. For several respondents, the University offered new opportunities:

I am grateful for the 'new technology' that my new job description has brought in its wake: the use of the Internet; the glass ceiling that has disappeared; the promise of a more intellectual atmosphere at work; a paradigm shift is like a new breeze. These are certainly advantages that I enjoy. (Interview 12)

These key words and phrases expressing positive emotions, applied to a definite minority but also signalled changing emotional dispositions as the process unfolded.

The emotional landscape of incorporation clearly requires further inquiry, along the lines pursued in the current work of Andy Hargreaves and his colleagues at the Ontario Institute for Studies in Education, where concepts such as the 'emotional geography of teaching' and 'leadership' 
are being provided with solid empirical scaffolding. What this initial survey of emotions reveals, however, are the changing, conflicting and catastrophic effects of incorporation on staff, all of which hold important implications for the change process in higher education.

\section{Synthesis of findings and critical appraisal}

One objective of this research was to devise an innovative methodology for researching lives. In this case, the College staff who lived through incorporation and found work within the University environment as a result would, through the facilitation provided in a series of research capacity building workshops, investigate the impact of this process on various aspects of their personal, professional and community lives. These staff members designed the interview protocol, tested it, and then administered the questions among themselves. The "sample" was therefore a self-selected one, excluding those staff members who left the campus either voluntarily taking the MASP offered by the provincial government or through re-deployment into the GDE.

The findings across the seven areas vary in terms of intensity and uniformity of experience. The most consistent experiences relate to perceptions of the role of management (that of the College, University and, to a lesser extent, the provincial government) in the process. Strong feelings of betrayal were articulated throughout the interviews. This was followed by equally strong expressions of uncertainty and discontent about the financial and family impacts of incorporation, inducing severe stress among the College staff members. This situation was aggravated by the long periods of uncertainty about their future employment. The professional experiences during incorporation suggested a dividing line in terms of relationships with colleagues (generally strained) and those with students (generally positive). Collegial relations were determined by who had been appointed, conditions of appointment (contract or permanent) and the institutional origins of the colleagues in question (the "full-blooded" University staff versus staff from the former "black" Colleges, versus the NKP staff). The impact of incorporation on the self-image and self-worth of College staff was definitive; the change in identity from teacher to researcher and from following the College schedule to the demanding University schedule resulted in a number of consequences for the career goals and family lives of the College lecturers. The emotional lives of the College staff passed through a veritable "see-saw" experience culminating for many in that one critical incident most frequently mentioned: "the day on which the names of the successful candidates were made known" (Interviews 1, 2, 7, 8, 12, 13, 14 and 23). This was the only theme in which the results were rather weakly dispersed across a range of experiences concerning the community life of the College lecturer.

In an attempt to critically appraise the research method, the participants were finally asked to write up reflective comments on how they had experienced the research process: Comments such as "[lt] was a harrowing experience. Yet, it was therapeutic too, in a way" (Reflection 6) suggest that participants had ascribed a curative value to the research process. Some 
believed the method increased validity since participants had worked together for many years. Not only had they bonded, but they had also felt comfortable sharing their painful experience of the incorporation process: "I also think that the joint publishing effort acted as a positive binding factor" (Reflection 4) and "We experienced a feeling of solidarity with colleagues and felt less isolated regarding the strong emotions and trauma we lived through" (Reflection 9). A few respondents felt this "self-research" would be meaningful only if it led to changes in the day-to-day working lives of the participants while two interviewees had been reluctant to share their feelings as they felt exposed or did not want to deal with their (negative) emotions again. A number of participants concluded that the value of reflecting after completing a research project such as this was not to be judged lightly. A productive offshoot of this research has been a group of colleagues now researching the experience of those staff members who were not appointed at the University.

Two issues were identified for further study. First, the research team remained conscious of the many silences detected in several of the interviews (Interviews 13, 14, 17 and 26). Often, staff would make a point about the fact that there were experiences that were emotionally too difficult to speak about or which would, if expressed, implicate senior staff, among other factors, about events that suggest negative and destructive actions during the incorporation process. If "silence" is another form of data representation, then this aspect of incorporation requires further inquiry. Second, corridor gossip and rumour play an important part in incorporation. Gossip creates illusions, shapes perceptions of actions, builds solidarity and influences personal choices, dispositions and emotions (Interviews 3, 7, 8, 9, 14,16 and 25). While not a central focus of this research, it is clear that empirical accounts of the role and influence of gossip in mergers require elaboration beyond singular studies available on this phenomenon (Tebutt and Marchington 1997).

What does this all mean? To some extent, the trauma of incorporation was inevitable given the stable, safe, secure and predictable lives of the original College staff. The recollection of sudden and intense trauma speaks volumes about the security of employment experienced under the college dispensation in South Africa. On the other hand, staff from the former 'black' colleges at Laudium and Soshanguve had already lived through experiences of disruption and relocation and, especially in this group there were feelings of despair, even fatalism, about the future. What is also clear, is that the management of the process was - in the eyes of the staff - a painful narrative of mistrust, distance and betrayal. The definitive perspective of the former College staff was that the 'human side' of the incorporation had clearly not been managed in a sensitive, open and consistent manner. The implications for post-incorporation institutional life are also very clear: although a more positive attitude toward change can be discerned, feelings of distrust continue and attitudes toward current managers could remain cautious and reserved long after the formalities of incorporation have been concluded. The most important lesson learned from this research project, therefore, is that in any institutional merger a certain degree of trauma, anxiety and uncertainty is inescapable; however, the failure to sensitively manage the 'human side' of 
mergers can have a negative impact on corporate ambitions and prolong the transformation of the merged institution. In the words of a former College staff member:

If I now look back it feels as if [this experience] belongs in the past, but I will never be able to erase it; for me, it was like hammering a nail into a beautifully polished piece of wood. The nail can be removed but the scar will always remain, even if you cover it with something. (Interview 9)

\section{Notes}

1. The research team would like to sincerely thank all those participants in the group for their willingness, under difficult circumstances, to reflect on the personal journeys undertaken in the course of the incorporation of the erstwhile Onderwyskollege Pretoria, translated as College of Education Pretoria, into the University of Pretoria. We trust that the experiences recorded here will counter the human costs of mergers and incorporations in higher education and, indeed, in all organisations.

2. The terminology associated with the combination of institutions is confusing, even misleading (Lang 2001). Typically, the local literature refers to "mergers" as a generic term that includes "incorporations" - the latter term referring specifically to the legislated requirement that colleges in South Africa be brought under the governance of universities and, in isolated cases, under the administration of a technikon.

3. The College was also known in the past, as Normaalkollege Pretoria (NKP), and had lived through several incorporations of former college entities, like Die Onderwyskollege Goudstad (a former white, Afrikaans institution); Transvaal College of Education - Laudium (a former Indian institution) and Transvaal College of Education - Soshanguve (a former "African" institution) when these closed. Both the College and the University are historically Afrikaans institutions, as will be evident from the research, but the University and the Faculty now conduct teaching, research and administration in English and Afrikaans.

4. There are several references in the interviews to Tuks or Tukkies, the colloquial name for the University of Pretoria drawn from its origins as the Transvaalse Universiteitskollege, or T.U.K. for short.

5. The Dean of the former Faculty of Education, responsible for academic concerns related to staff incorporation, employed a consultant to determine exactly how many staff positions from the College were required to ensure long-term financial sustainability as well as a healthy curriculum revitalisation that could result from the incorporation. The consultant recommended substantially fewer posts than the 96 available, in part because of the fact that the student: lecturer ratios in colleges of education were much smaller than those required for universities.

6. The decisions as to which staff would be permanently appointed, and which on contract, entailed the typical vagaries of predicting which subjects would be continued on a long term basis as part of a university curriculum and which subjects were "viable" in terms of long term existence given extremely low enrolments in such subject areas. 
7. This training falls under the management of the Dean's Office; the Dean also assumes a primary role in the training of the former College staff, although other colleagues in the Faculty have also led certain modules. In the training week that produced this research, the Dean acted as facilitator of both the research process and the writing tasks.

\section{References}

Buono, A.R. and Bowditch, J.L. (1989). The Human Side of Mergers and Acquisitions: Managing Collisions between People, Cultures and Organisations. San Francisco, California: Jossey Bass Publishers.

Eastman, J. and Lang, D.W. (2001). Mergers in Higher Education: Lessons from Theory and Experience.

Goedegebuure, L.C.J. (1992). Mergers in Higher Education: A Comparative Perspective. Enschede: Universiteit Twente.

Habib, A. and Parekh, A. (2000). 'Transforming South Africa's university system: The case for strategic mergers', Perspectives in Education 18(3), 3951.

Harman, G. (2000). 'Institutional mergers in Australian higher education', Higher Education Quarterly 54(4), 343-366.

Hay, H.R., Fourie, M. and Hay, J.F. (2001). 'Are institutional combinations, mergers or amalgamations the answer? An investigation into staff perceptions', South African Journal of Higher Education 15(1), 100-108.

Kirk, G. (2000). Policy and Practice in Education: Enhancing Quality in Teacher Education. Scotland: Dunedin Academic Press.

Kotecha, P. and Harman, G. (2001). Exploring Institutional Collaboration and Mergers in Higher Education. Pretoria: South African University ViceChancellors Association.

Tebbutt, M. and Marchington, M. (1997). ' 'Look before you speak': Gossip and the insecure workplace', Work, Employment and Society 11(4), 713-735.

Reddy, Jairam (2000). 'Response to the task team of the council on higher education: A macro-level perspective', Perspectives in Education 18(3), 166174. 